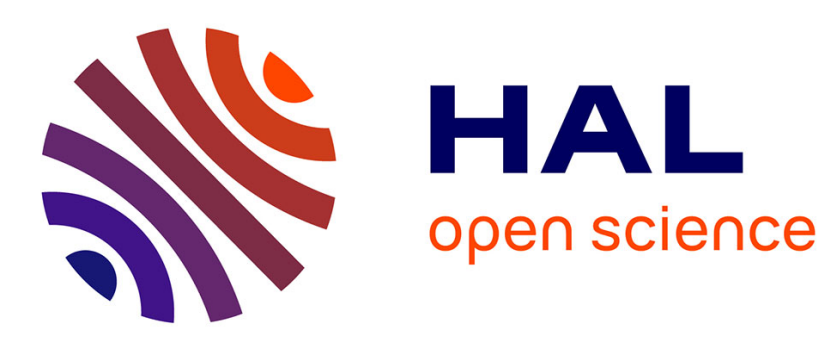

\title{
Passively Q-Switched Ytterbium- and Chromium-doped All-Fiber Laser
}

\author{
Bernard Dussardier, Jerome Maria, Pavel Peterka
}

\section{To cite this version:}

Bernard Dussardier, Jerome Maria, Pavel Peterka. Passively Q-Switched Ytterbium- and Chromium-doped All-Fiber Laser. Applied optics, 2011, 50 (25), Manuscript ID: 143929. 10.1364/AO.50.000E20 . hal-00589246

\section{HAL Id: hal-00589246 https://hal.science/hal-00589246}

Submitted on 28 Apr 2011

HAL is a multi-disciplinary open access archive for the deposit and dissemination of scientific research documents, whether they are published or not. The documents may come from teaching and research institutions in France or abroad, or from public or private research centers.
L'archive ouverte pluridisciplinaire HAL, est destinée au dépôt et à la diffusion de documents scientifiques de niveau recherche, publiés ou non, émanant des établissements d'enseignement et de recherche français ou étrangers, des laboratoires publics ou privés. 


\title{
Passively Q-Switched Ytterbium- and Chromium-doped
} All-Fiber Laser

\author{
Bernard Dussardier, ${ }^{1, *}$ Jérôme Maria, ${ }^{1}$ Pavel Peterka ${ }^{2}$ \\ ${ }^{1}$ Laboratoire de Physique de la Matière Condensée, Université de Nice Sophia-Antipolis, \\ CNRS, UMR 6622, Parc Valrose, 06108 Nice Cedex 2, France \\ ${ }^{2}$ Institute of Photonics and Electronics AS CR, v.v.i., 18251 Prague, Czech Republic \\ *Corresponding author: bernard.dussardier@unice.fr
}

A chromium-doped saturable absorber fiber stabilizes an otherwise spontaneously chaotically self-pulsing ytterbium-doped fiber laser . This original passively Q-switched all-fiber laser produces sustained and relatively stable trains of smooth pulses at high repetition rate.

(C) 2011 Optical Society of America

OCIS codes: 060.2320 Fiber optics amplifiers and oscillators, 060.3510 Lasers, fiber, 140.3540 Lasers, Q-switched, 140.3615 Lasers, ytterbium, 140.4050 Mode-locked lasers, 140.5680 Rare earth and transition metal solid-state lasers

\section{Introduction}

The development of Q-switched fiber lasers is an alternative to bulk pulsed solid-state lasers operating in the ns- to $\mu$ s-range for many applications such as material processing, medicine, aerial or space communications, remote sensing in free space or in fiber systems. Fiber laser 
systems benefit from the high versatility and reliability of integrated, factory-aligned and fusion spliced fiber devices, relying on fiberized components produced at low cost and having high damage threshold. However most Q-switched fiber lasers use externally driven intracavity bulk modulators, or bulk passive components such as a bulk polarizer [1], or a semiconductor saturable absorber mirror [2]. These must be located in a free space section of the cavity, causing alignment and reliability problems.

The development of "all-fiber" passively Q-switched (PQS) fiber lasers is interesting because, as all components are pre-aligned, the device stability, damage threshold and reliability are high. Also, no external electronic driver is needed, though some may need additional cheap and slow feedback control systems. Transition metal-doped bulk crystals have been used as saturable absorber (SA) within PQS fiber lasers [3,4], however alignment and optical damage were critical. We have for the first time proposed a core-pumped, low power, all-fiber PQS laser [5] using a newly developed chromium-doped fiber [6] as integrated SA (CrSA). Since, few PQS fiber lasers have implemented alternative SA ions like rare-earth ions (holmium [7], thulium [8], samarium [9]) or metals (bismuth [10]). However, some of these SA have drawbacks: low saturation intensity, long response time, absorption band narrower than the gain curve or wavelength-shifted relative to the gain medium. These characteristics necessitate additions to the laser cavity, resulting in more complex devices $[7,10]$. As for bulk SA, some transition metals from the $3 \mathrm{~d}$ series, like $\mathrm{Cr}^{4+}$ ions, are in principle the most attractive SA in silica in the near infrared, because of their high transition strength over broad wavelength ranges [11] and short response time [12]. A waveguidesaturable absorber was fabricated by femtosecond pulses in YAG: $\mathrm{Cr}^{4+}$ to implement PQS in a hybrid all guided device [13].

Other fiber laser systems produce self-pulsing in the sub- $\mu$ s domain. Regular selfpulsing in erbium highly-doped fibers was studied, based on energy transfers within the gain medium [14]. However this principle allows only a limited potential for engineering and 
optimization. More recently, double-clad ytterbium-doped fiber (DCYF) lasers have raised a great interest. However DCYF lasers have the particularity to randomly self-pulse in some cases. In particular, linear cavities with high loss and/or non-uniform population inversion induce chaotic pulse generation [15]. Two main operating regimes are observed: the sustained self-pulsing (SSP), having a period longer than the cavity round-trip time, and the self modelocking (SML), of which period is equal to the cavity round-trip time) [16].

In this paper, we take advantage of the self-pulsing phenomenon in DCYF lasers and study the effect of a CrSA fiber inserted in the cavity on the laser dynamics. We show that the "DCYF alone" laser has a chaotic pulsed behaviour (both SSP and SML) at any pump level above threshold, whereas in presence of the Cr-doped fiber SA, relatively stable and sustained PQS pulses trains are produced.

\section{Experimentals}

\section{Characteristics of the Ytterbium- and Chromium-Doped Fibers}

The DCYF and the single-mode CrSA fiber were prepared at LPMC by MCVD and solution doping technique. The DCYF has a D-shaped cladding $(125 \times 100 \mu \mathrm{m})$ for high pump absorption $(3.8 \mathrm{~dB} / \mathrm{m}$ at $975 \mathrm{~nm})$. The diameter and numerical aperture (NA) of its singlemode core are $7 \mu \mathrm{m}$ and 0.11 , respectively. The cladding NA is 0.38 . The CrSA was doped with $\mathrm{Cr}^{4+}$ ions only [11], having a broadband absorption band across the visible and infrared wavelength range [6] and a composite SA relaxation behaviour [12]. Its core absorption is $3.5 \mathrm{~dB} / \mathrm{m}$ at $1064 \mathrm{~nm}$ and its mode-size is adapted to that of the DCYF.

\section{Fiber Laser Setups}

Two laser setups were studied. The first used only the DCYF (length $1.2 \mathrm{~m}$, pump absorption $<5 \mathrm{~dB}$ ). The cavity was formed by a fiber Bragg grating (FBG) with high reflectivity 
$(>99,5 \%)$ at $1064 \mathrm{~nm}$ (bandwidth $0.3 \mathrm{~nm}$ ) and the perpendicular cleaved end of the DCYF

(Fig. 1). The cavity was $\sim 6.1 \mathrm{~m}$ long. The collimated pump beam from a $20-\mathrm{W}, 105-\mu \mathrm{m}$ diameter and 0.2 NA, multimode fiberized 975-nm laser diode was launched into the DCYF cladding using a x1 magnifying aspherical lenses system through the cleaved output end of the DCYF. The polarization controller (PC) was used to partially control the laser stability. The FBG was limiting the number of longitudinal modes. Note that the pump coupling was intentionally not optimized: the NA and the area of the pump beam did not match that of the DCYF D-shaped cladding. Therefore pumping of the $\mathrm{Yb}^{3+}$ populations was not homogeneous, providing favorable conditions for sustained self-pulsing (SSP). Also, this cavity was designed to self generate short pulses, therefore a short cavity length, a relatively high unsaturable loss and high $\mathrm{Yb}^{3+}$ inversion factor were chosen. As a consequence, the laser slope efficiency was not optimized. That also increased the threshold of appearance of stimulated Brillouin scattering (SBS) far above the achieved output power in this study. Therefore SBS had not effect on the reported results. In the second setup, $0.3 \mathrm{~m}$ of CrSA was fusion-spliced between the FBG and the PC. (Fig. 1). The output beam was collected backward relative to the pump beam and was directed using a dichroic mirror toward a powermeter or a $1 \mathrm{GHz}$ InGaAs detector connected to a fast oscilloscope or an optical spectrum analyser.

\section{Results}

The characteristics of both laser configurations are shown on Fig. 2. The 'DCYF only' laser threshold and slope efficiency vs. the incident pump power were $0.45 \mathrm{~W}$ and $22 \%$, respectively. The DCYF laser had a chaotic behaviour randomly switching between CW and Q-switched operating modes over the whole pumping range. A characteristic time trace of the output is shown on Fig. 3(a), typical of such cavity [3-5,7-10,13]. The few $\mu$ s-long pulse envelopes were strongly modulated by short pulses with the period of one cavity return-trip 
time (Fig. 3(b)). Here we observe a combination of SSP and SML [16]. Using the PC to stabilize the output was quite inefficient, and at best produced a very noisy laser output. The chaotic behavior was always dominant. Another short section of a commercially available $\mathrm{Yb}^{3+}$-heavily doped fiber, implemented in the same conditions, produced the same results.

By inserting a piece of CrSA fiber in the cavity, the characteristics of the laser changed drastically : first, the threshold of the laser increased and its efficiency diminished, as usually observed when inserting a SA in a cavity (Fig. 2). The CrSA fiber caused the threshold to increase up to $1.0 \mathrm{~W}$, and the slope efficiency to lower down to $6 \%$. Although the obtained slope efficiency is less than in systems implementing non-linear polarization rotation in fibers $(\sim 30 \%)$ [1] or bulk $\mathrm{Co}^{2+}$-ZnSE crystal $(\sim 15 \%)$ [3], is compares well with all-fiber systems implementing rare-earth or $\mathrm{Bi}$ ions (up to $\sim 10 \%$ ) $[7,8,9,10]$. Our result constitutes in improvement in all-fiber PQS systems using transition metal SA, compared to former reports in fiber [5] or external guided-wave Cr-doped saturable absorbers [13] (around $1 \%)$.

More importantly, the $\mu$ s-long pulse trains were efficiently stabilized over the whole available pump range. On Fig. 4(a) is shown a typical output at 7.6 times the threshold. The peak RMS fluctuations were less than $10 \%$ at 9.4 times the threshold. The higher the pump, the better the stability. Up to the maximum available pump (16 W, measured at the fiber input end), the stable passive Q-switching was still present, and no transition to CW operation was observed. The Q-switched envelopes were smoothed compared to the 'DCYF only' laser. No sub-modulation at the return trip period was visible anymore (Fig. 4(b)). The pulse duration and repetition rate versus incident pump power of the DCYF + CrSA laser are shown on Fig. 5, with a $480 \mathrm{~ns}$ minimum pulse width, a repetition rate as high as $350 \mathrm{kHz}$, a $2 \mu \mathrm{J}$ pulse energy and peak power equal to $6.4 \mathrm{~W}$.

\section{Discussion}


The behaviour of the DCYF+CrSA laser is typical of a PQS mode of operation. It must be noted that this results were obtained with a set of cavity parameters causing self-pulsing or chaotic behaviour in the 'DCYF only' laser. Indeed, when the CW or a relatively stable output beam was set in the DCYF laser (by choosing parameters or setting the PC), then adding the CrSA provided only a quasi-CW regime. It is evident near the threshold of the $\mathrm{DCYF}+\mathrm{CrSA}$ laser, when the pulse peak power is still too weak to induce the CrSA fiber to saturate : then the behavior is fully chaotic. When the pump increases, the laser behavior steadily shifts toward a stable Q-switched regime. The capacity of our CrSA to stabilize SSP and cancel out SML phenomena in an $\mathrm{Yb}^{3+}$-doped fiber laser has never been reported, to the best of our knowledge. The reasons of the stabilization are not fully understood yet. It is tentatively proposed that SA relaxation time constants spread over decades within the population of SA ions in the glass (as observed in $\mathrm{Cr}^{3+}$-doped glasses [17]) act in different ways: "slow" saturable absorbers would maintain the SSP process, whereas "fast" ones would dampen the rapid optical fluctuations from the SML phenomenon. Modelling the laser behaviour according to this proposal is under progress, using a fully space- and time-resolved model.

In this particular cavity design and parameters, the shortest possible pulses were achieved, downto $\sim 480$ ns. To further shorten them, a more compact cavity comprising only the active fibers $(1.5 \mathrm{~m})$ would produce sub-100-ns-pulses. Then the pulse peak power would be increased, causing a stronger CrSA saturation, and hence the pulse energy and the slope efficiency would be larger. In order to stay below the threshold of non-linear effects, mode size enlargement will be required by introducing large-mode area fiber technology. The obtained pulsed laser source reported here could serve as a seed in a MOPA configuration using a power DCYF amplifier, so that much higher pulse energy and/or peak power, as well as shorter duration would be accessible for applications, such as long haul ranging or precision machining. 


\section{Conclusions}

In conclusion, we have shown the potential of a CrSA fiber to produce stable passively Qswitched pulses trains out of a DCYF laser. This is to our knowledge, the first demonstration of such a laser with the active elements $\mathrm{Yb}^{3+}$ and $\mathrm{Cr}^{4+}$. This laser architecture could be integrated and power upgraded, with great potentials for sub-microsecond, high energy pulsed applications.

\section{Acknowledgements}

The author acknowledge partial support from: "Fédération Doeblin" (CNRS, France), grant MSMT-Kontakt ME10119 (Czech Rep.) and the Czech-French 'Barrande' program 17360VA (EGIDE-France and Czech Academy of Sciences). LPMC is with GIS 'GRIFON' (CNRS, http://grifon.xlim.fr/).

\section{References}

1 A. Hideur, T. Chartier, M. Brunel, M. Salhi, C. Özkul, and F. Sanchez, "Mode-lock, Qswitch and $\mathrm{CW}$ operation of an $\mathrm{Yb}$-doped double-clad fiber ring laser," Opt. Comm. 198, 141-146 (2001).

2 R. Paschotta, R. Häring, E. Gini, H. Melchior, U. Keller, H. L. Offerhausand D. J. Richardson, "Passively Q-switched 0.1-mJ fiber laser system at $1.53 \mu \mathrm{m}$," Opt. Lett. 24, 388-390 (1999).

3 M. Laroche, A. M. Chardon, J. Nilsson, D. P. Shepherd, W. A. Clarkson, S. Girard, and R. Moncorgé, "Compact diode-pumped passively Q-switched tunable Er-Yb doubleclad fiber laser," Opt. Lett. 27, 1980-1982 (2002).

4 V. N. Filippov, A. N. Starodumov, and A. V. Kir'yanov, “All-fiber passively Qswitched low-threshold erbium laser," Opt. Lett. 26, 343-345 (2001). 
5 L. Tordella, H. Djellout, B. Dussardier, A. Saissy, and G. Monnom, "High repetition rate passively Q-switched $\mathrm{Nd} 3+: \mathrm{Cr} 4+$ all-fibre laser," Electron. Lett. 39, 1307-1308 (2003).

6 V. Felice, B. Dussardier, J. K. Jones, G. Monnom, and D. B. Ostrowsky, "Chromiumdoped silica optical fibres : influence of the core composition on the $\mathrm{Cr}$ oxidation states and crystal field," Opt. Mat. 16, 269-277 (2001).

7 A. Kurkov, E. M. Sholokhov, and O. I. Medvedkov, "All fiber Yb-Ho pulsed laser," Laser Phys. Lett. 6, 135-138(2009).

8 A. S. Kurkov, Ya. E. Sadovnikova, A. V. Marakulin, and E. M. Sholokhov, "All fiber Er-Tm Q-switched laser", Laser Phys. Lett. 7, $795-797$ ( 2010).

9 A. A. Fotiadi, A.S. Kurkov, and I. M. Razdobreev, "Dynamics of All-Fiber Self-Qswitched Ytterbium/ Samarium Laser," in Conference on Lasers and Electro-Optics (CLEO’07) (OSA,2007), Baltimore, USA, doi : 10.1109/CLEO.2007.4452479

10 V. V. Dvoyrin, V. M. Mashinsky, and E. M. Dianov, "Yb-Bi pulsed fiber lasers," Opt. Lett. 32, 451-453 (2007).

11 V. Felice, B. Dussardier, J. K. Jones, G. Monnom, and D. B. Ostrowsky, "Cr4+-doped silica optical fibres : absorption and fluorescence properties,” Eur. Phys. J.AP, 11, 107$110(2000)$

12 B. Dussardier, Y. Guyot, V. Felice, G. Monnom, and G. Boulon, "Cr4+-doped silicabased optical fibers fluorescence from $0.8 \mu \mathrm{m}$ to $1.7 \mu \mathrm{m}$," in Proc. Advanced Solid State Lasers conference (ASSL'02), in Trends in Opt. \& Photon. Series (TOPS, ISBN: 155752-697-4), 68, 104-108, (2002).

13 A. G. Okhrimchuk, V. K. Mezentsev, V. V. Dvoyrin, A. S. Kurkov, E. M. Sholokhov, S. K. Turitsyn, A. V. Shestakov, and I. Bennion, "Waveguide-saturable absorber fabricated by femtosecond pulses in YAG: $\mathrm{Cr}^{4+}$ crystal for Q-switched operation of $\mathrm{Yb}$-fiber laser," Opt. Lett. 34, 3881-3883 (2009).

14 F. Sanchez, P. Le Boudec, P.-L. François, and G. Stephan, "Effect of ion pairs on the dynamics of erbium-doped fiber lasers," Phys. Rev. A 48, 2220-2229 (1993). 
15 B. N. Upadhyaya, U. Chakravarty, A. Kuruvilla, S.M. Oak, M.R. Shenoy, and K. Thyagarajan, "Self-pulsing characteristics of a high-power single transverse mode $\mathrm{Yb}$ doped CW fiber laser," Opt. Comm. 283, 2206-2213 (2010).

16 F. Brunet, Y. Taillon, P. Galarneau, and S. LaRochelle, "A Simple Model Describing Both Self-Mode Locking and Sustained Self-Pulsing in Ytterbium-Doped Ring Fiber Lasers," J. Light. Technol. 23, 2131 (2005).

17 M. Grinberg, D.L. Russell, K. Holliday, K. Wisniewski , Cz. Koepke, "Continuous function decay analysis of a multisite impurity activated solid," Opt. Comm. 156, 409418 (1998). 


\section{Figure captions list}

Fig. 1: Laser setup. DCYF: double-clad $\mathrm{Yb}^{3+}$-doped fiber, PC: polarization controler, CrSA: Cr-doped saturable absorber fiber, FBG: highly reflecting fiber Bragg grating at $1064 \mathrm{~nm}, \mathrm{FWHM}=0.3 \mathrm{~nm}$. The pump is a $20-\mathrm{W}$ multimode fiber coupled CW laser diode. The HR dichroic mirror at $1.06 \mu \mathrm{m}$, transmits $90 \%$ at pump wavelength. The $11-\mathrm{mm}$ focal length lenses system has a unit magnification.

Fig. 2: Fiber laser integrated output vs incident pump power. 0 : 'DCYF only', $\square$ : 'DCYF $+\mathrm{CrSA}^{\prime}$. Thresholds $=0.45$ and $1.7 \mathrm{~W}$, slope efficiencies $=22 \%$ and $6 \%$, maximum output power $=3 \mathrm{~W}$ and $0.9 \mathrm{~W}$, respectively.

Fig. 3 : (a) 'DCYF only' laser output, for $1 \mathrm{~W}$ of pump (2.2 times threshold). (b) zoom on one typical pulse envelope.

Fig. 4 : (a) 'DCYF+CrSA' laser output, for $7.6 \mathrm{~W}$ of pump (7.6 times threshold). (b) zoom on a typical pulses series.

Fig. 5 : Pulse characteristics of the 'DCYF + CrSA' laser. 
Fig. 1

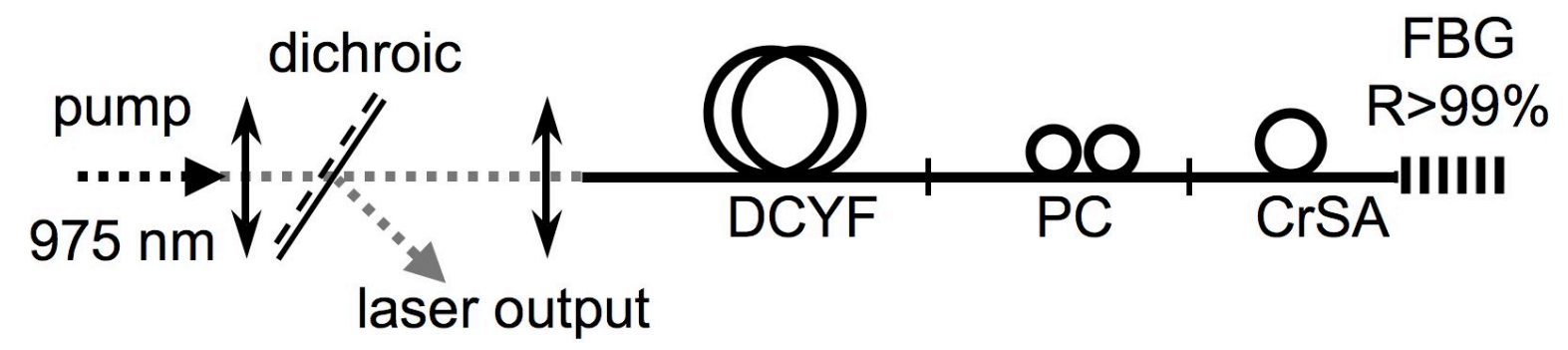

Fig. 2

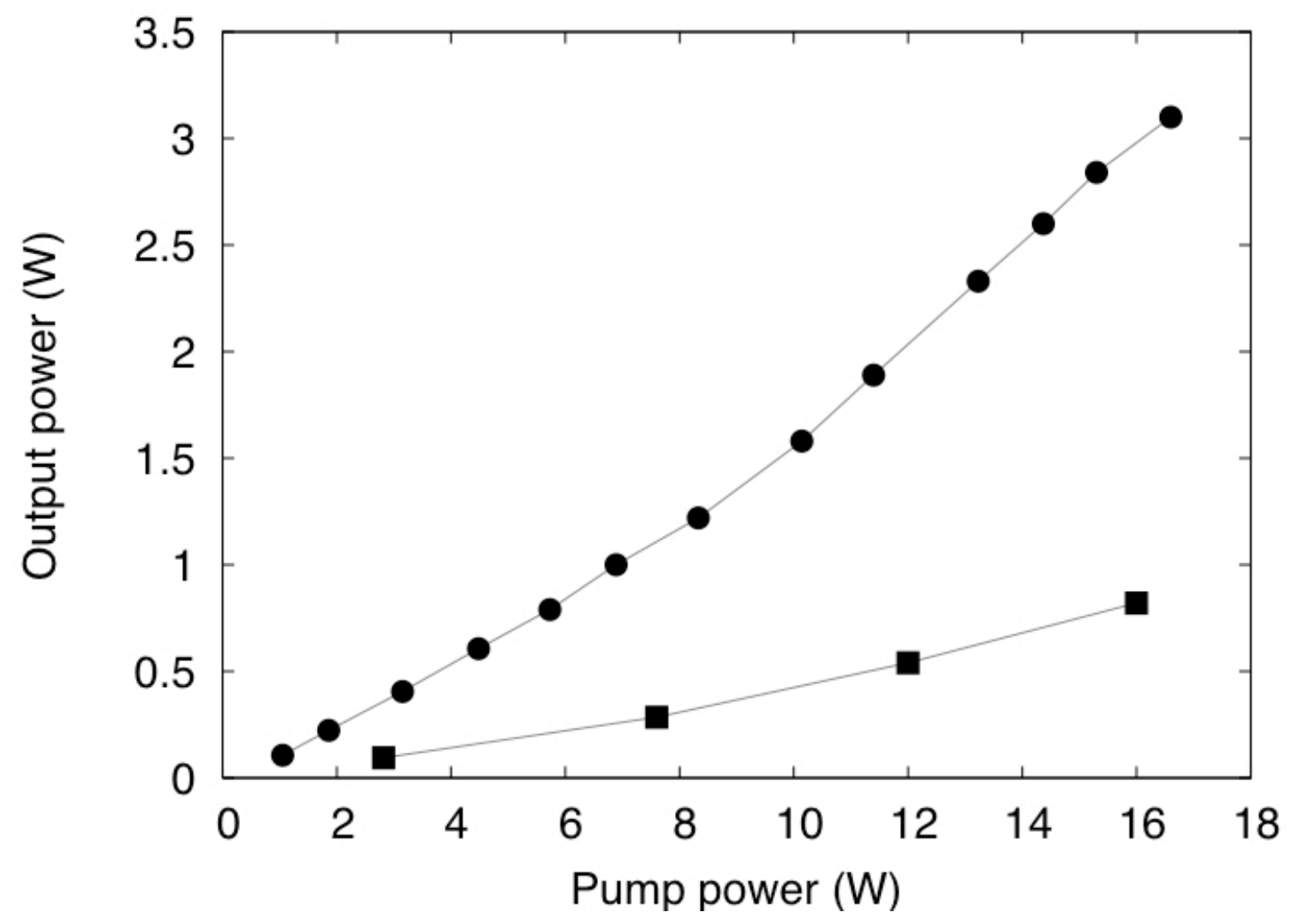


Fig. 3

(a)

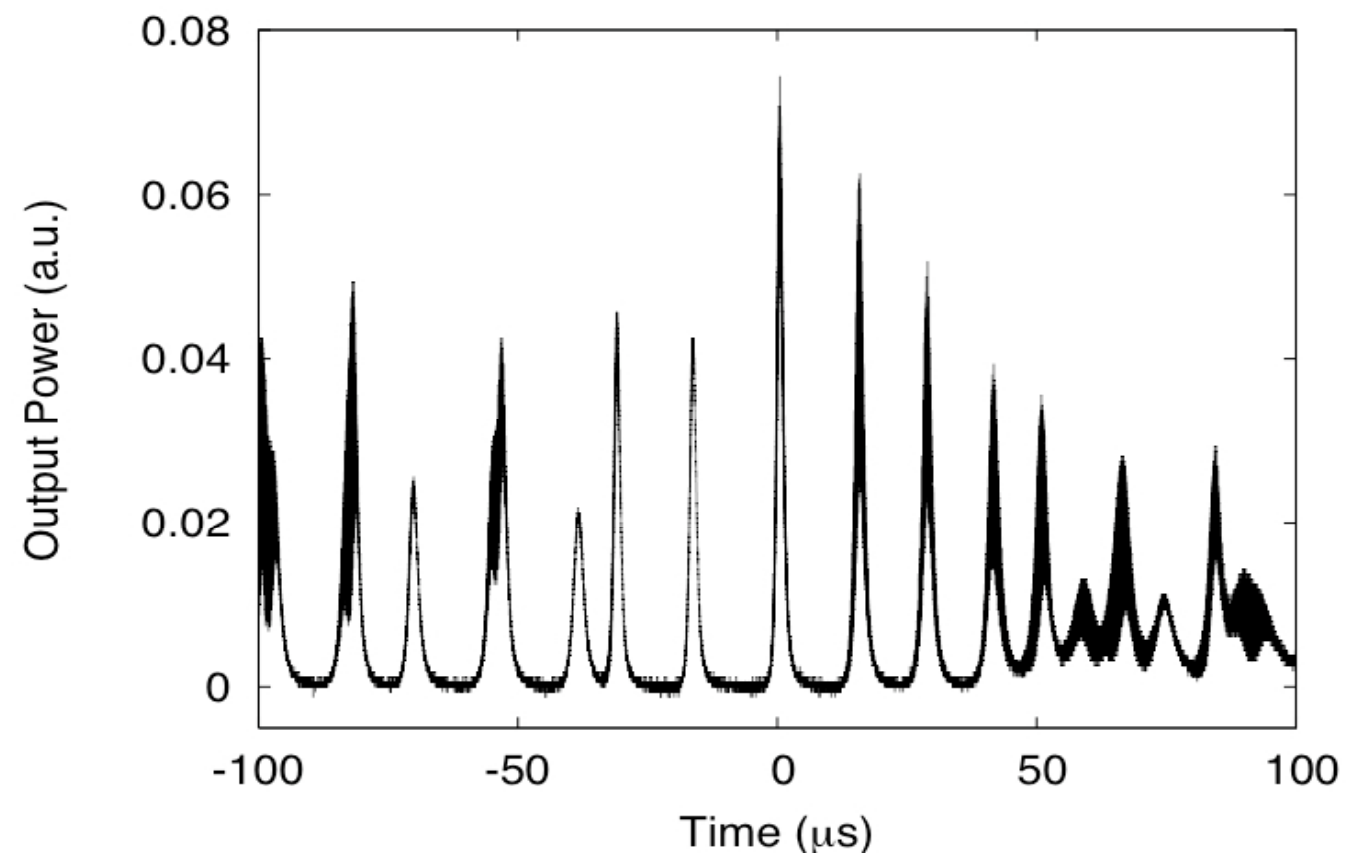

(b)

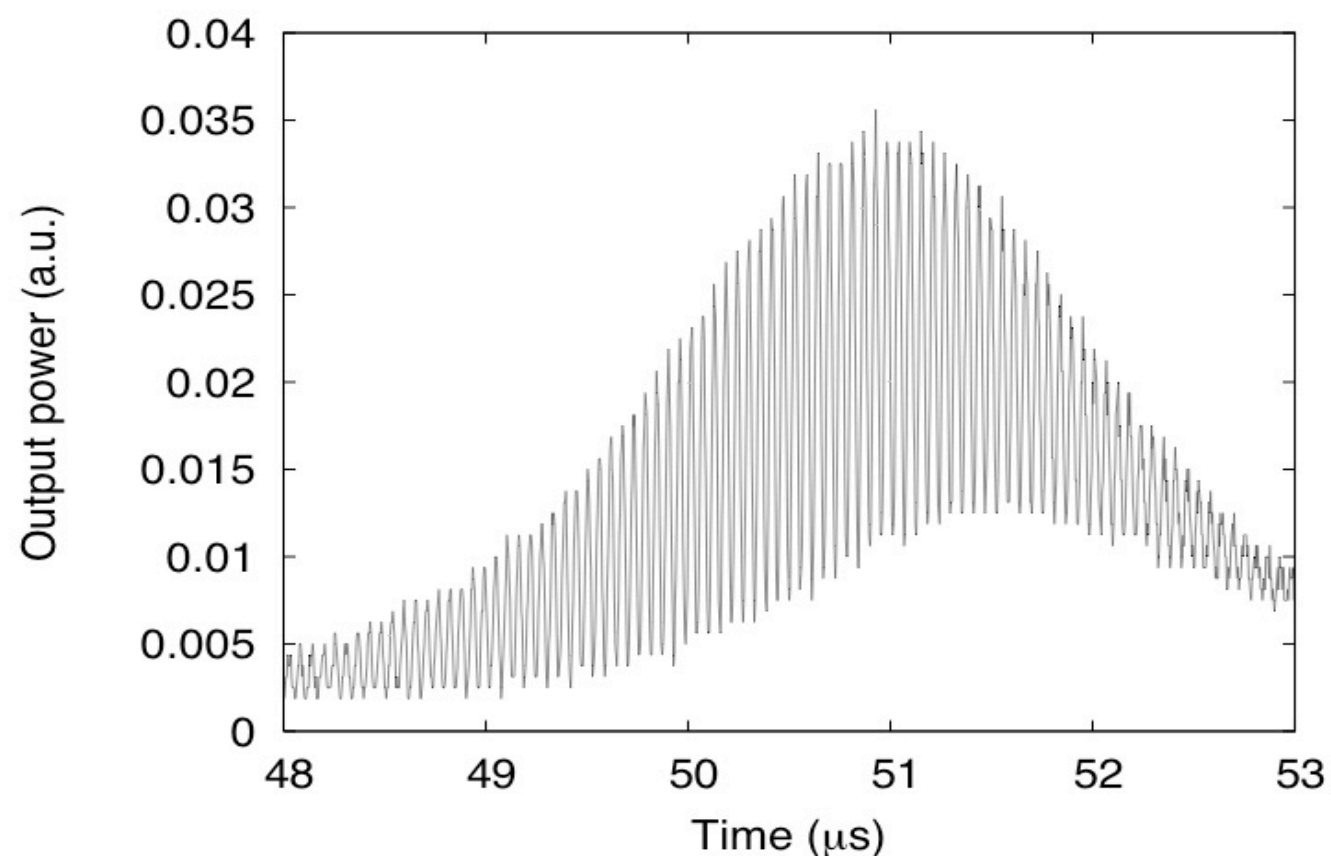


Fig. 4

(a)

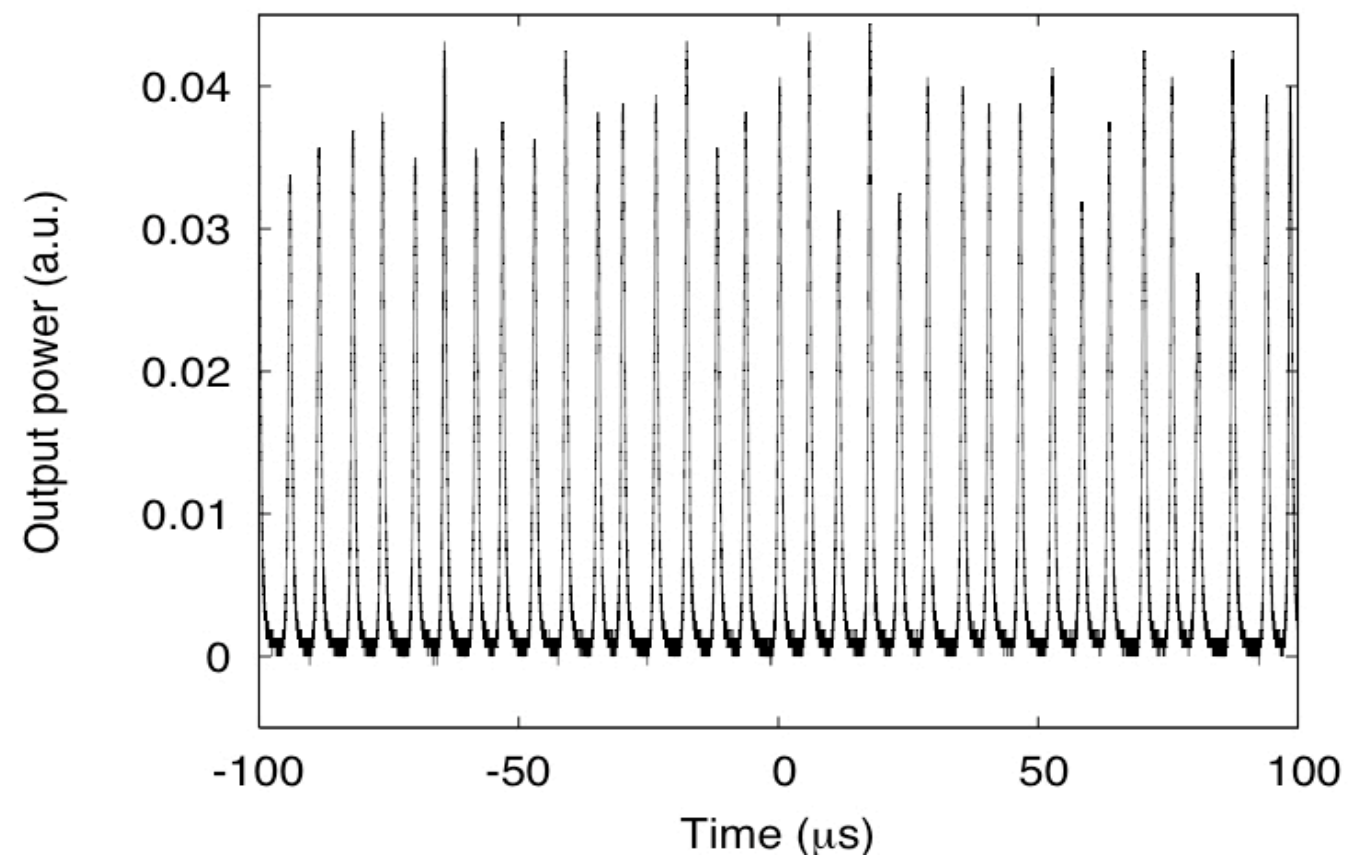

(b)

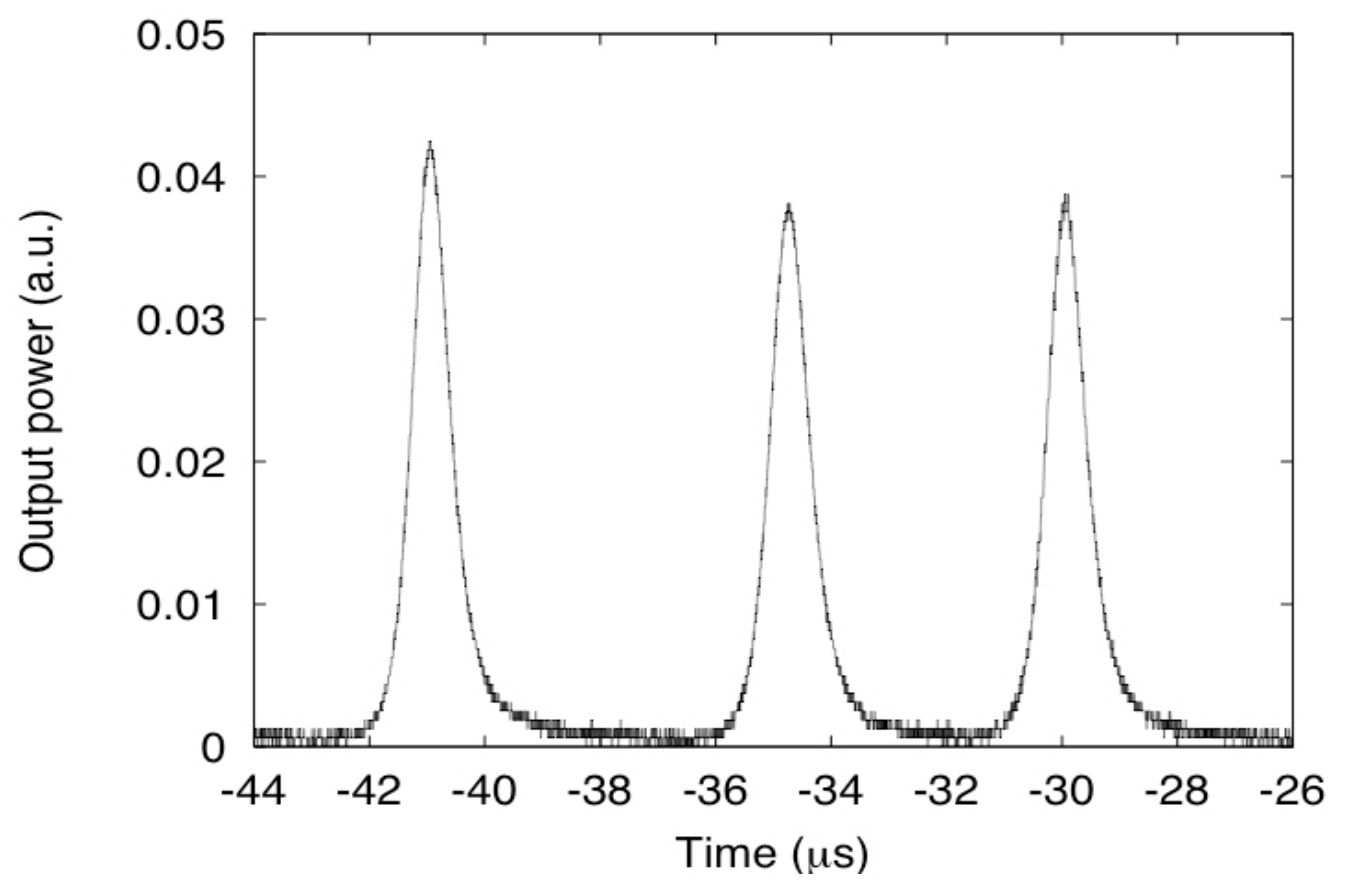


Fig. 5

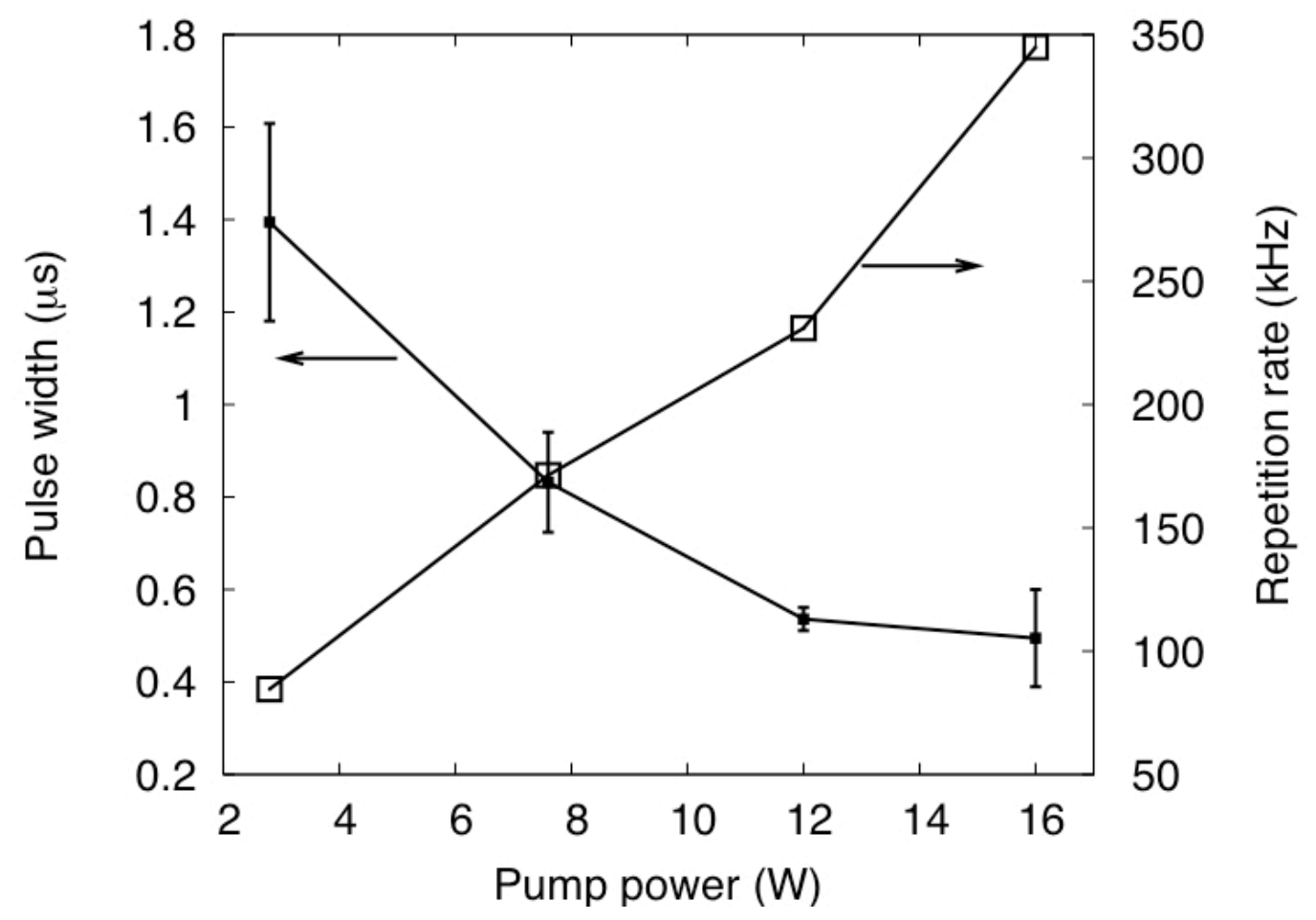

